I46 The British Journal of Inebriety

\title{
MEDICATED WINES AND ALCOHOL ADDICTION.
}

BY J. S. BOOTHROYD, M.D., J.P.

DURING the last few years there has been a very decided boom in certain sophisticated wines--"Dietetic," "Tonic," or "Restorative" beverages. In advertisements concerning them the subsidiary ingredients are not infrequently set forth, and consist of well-known medicinal or nutrient preparations. Medical approval is often quoted in support of their use, and it is claimed that the therapeutic effects far transcend those of wines pure and simple. Undoubtedly the public imagination has been captured by the ingenious methods pursued in pushing these productions. The medical practitioner is constantly being asked for his opinion regarding them, and he finds that, in many households from which alcoholic drinks have been hitherto excluded, these wines are now innocently, but freely used. It behoves medical men, therefore, to take the matter into their very serious consideration.

Some months ago the British Medical Journal performed a great public service by undertaking a series of analyses of the wines in question, with remarkably interesting results. The most widely known and urgently puffed is undoubtedly "Wincarnis," frankly advertised as consisting of port wine, Liebig's Extract, and extract of malt.

It is difficult for the public to withstand the allurements of such a combination of " powerful restoratives, recommended by thousands of medical men."

The British Medical Journal gives the result of its analysis of "Wincarnis" as follows : 


\begin{tabular}{|c|c|c|c|}
\hline $\begin{array}{l}\text { Alcohol - } \\
\text { Total solids }\end{array}$ & $\begin{array}{l}- \\
-\end{array}$ & $\begin{array}{l}19 \cdot 6 \text { per } c \\
20^{\circ} 9 \text { parts }\end{array}$ & $\begin{array}{l}\text { measure. } \\
\text { uid parts. }\end{array}$ \\
\hline Meat extract & ulated from & & \\
\hline nitrogen) & $-\quad-\quad-$ & $1 \cdot 2$ & ," \\
\hline Fixed acidity & - & 0.26 part & ," \\
\hline Volatile acidity & - & $0.09 \quad$, & ", \\
\hline Reducing sugat & alculated & & \\
\hline glucose) & 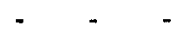 & $18 \cdot 2$ parts & , \\
\hline Ash & - & 0.4 part & , \\
\hline
\end{tabular}

A wineglassful would therefore contain 3 drachms of pure alcohol, $10^{\circ} 5$ grains of meat extract, 159 grains of glucose. Now, roughly speaking, 10 grains of meat extract would be equivalent to about six small teaspoonfuls of ordinary bouillon. It is this minute and negligible factor which differentiates "Wincarnis" from ordinary port and gives it its marvellous restorative powers ! He would be a highly imaginative man who would attach therapeutic importance to the malt extract it contains.

In other less known meaty wines the percentage of meat extract varies from 0.5 to 3.4 .

With regard to the "Tonic" wines, the principal ingredients are coca and cinchona, the amount ranging from a minute quantity to the equivalent of 21 minims of liquid extract of coca and 12 minims of the liquid extract of cinchona respectively. The most aggressively and ingeniously advertised of these "Tonic" wines is "Hall's Tonic Wine," formerly known as "Hall's Coca Wine." In this the alcohol amounts to $17 \cdot 85$ per cent., and the alkaloid to $0^{\circ} 003$. The total quantity extracted from over half a pint of wine is barely sufficient to cause an appreciable numbing when applied to the tongue.

No medical man can study the results of the investigations of the British Medical Journal without forming a very decided opinion as to the claims made by the vendors of these much-vaunted preparations. Of the great majority, and especially of those most puffed in the newspapers and advertised in the press and on public hoardings, it may be safely affirmed that they have no appreciable therapeutic influence other than that possessed by any of the ordinary wines in the market.

The seriousness of the situation lies in this, that they contain from 16 to 20 per cent. of alcohol-an amount equal to that of port and sherry, and double that of claret or hock. Clearly the

$$
\text { 13-2 }
$$




\section{The British Journal of Inebriety}

public consume, and are in danger of acquiring a taste for, these strong drinks under the wholly wrong impression that they have exceptional medicinal virtues.

In these days of diminishing faith in alcohol as such, there is a grave social danger in the fact that strong alcoholic drinks are being foisted upon an unsuspecting public under the specious guise of medicinal and dietetic beverages.

It is obvious that a serious responsibility rests upon those medical practitioners who recommend their indiscriminate use. 